SESSION $\underline{3630}$

\title{
BEST PRACTICES IN ENGINEERING EDUCATION: IS THE IMPACT GENDERED?
}

\author{
Harriet Hartman, Moshe Hartman \\ Department of Sociology, Rowan University
}

\begin{abstract}
This paper presents results from an NSF-funded study of engineering students at Rowan University. Only five years old, the infrastructure of Rowan's engineering program has incorporated many of the elements believed to facilitate the retention and success of women in engineering. Hands-on lab work and interdisciplinary, cooperative teamwork are cornerstones of all levels of the undergraduate program; communication skills are integrated into the curriculum; a low faculty-student ratio and class size insure individualized attention; ample opportunities for industry-based internships exist. Under such conditions, do female students flourish alongside the male students? The study compares male and female students' satisfaction with various aspects of the program and climate in the Engineering College, and shows variation in gender differences by year in the program. The analysis shows that female students are as satisfied or more satisfied than the male students with the programmatic elements of demands on the students in the classroom and in the curriculum, the applied aspects of the program in terms of labwork, teamwork and Rowan's engineering clinic, and peer and student-faculty relationships. The paper concludes with a discussion of the implications of the findings in terms of whether the practices of the Rowan program are indeed best practices in engineering education, and not for women only.
\end{abstract}

\section{Introduction}

The national shortage of engineers has led to scrutiny of the "pipeline" which leads from interest in the sciences in the childhood years through career commitment to the field. Critical in this journey are the undergraduate years. Astin and Astin ${ }^{1}$ estimated $40 \%$ attrition in engineering during the undergraduate years; Strenta et. al. ${ }^{2}$ reported $40-60 \%$ attrition in engineering for men and even higher, $54-70 \%$, attrition for women; Adelman $^{3}$ shows a persistent $20 \%$ gap nationally between men's and women's completion rates of the undergraduate degree in engineering. Staying in engineering during the undergraduate years is intricately tied to student satisfaction with their major ${ }^{4,5,6,7}$. In a study of over 6000 women at 53 institutions, happiness with their major was one of the main differences between those who stayed in engineering and those leaving it $^{8}$.

Previous research suggests that student satisfaction with their undergraduate experience is positively affected by departmental atmosphere, including quality of teaching, class size, and faculty support ${ }^{1,6,8}$, being able to work on research with a faculty member or independently ${ }^{1}$, and

\footnotetext{
"Proceedings of the 2002 American Society for Engineering Education Annual Conference \& Exposition Copyright (C) 2002, American Society for Engineering Education”
} 
course atmosphere (including competitiveness, time spent on course, the pace and workload) ${ }^{8}$; pedagogy used all too often in engineering schools, emphasizing competition, weeding outindividual achievement, and autonomous (as opposed to collaborative) work have been seen as contributing to a "chilly climate" for women in particular ${ }^{7,9,10,11,12}$, leading to women's dissatisfaction with the course of study, alienation, and beliefs that they cannot succeed or do not have the ability or knowledge to succeed in the science, mathematics \& engineering disciplines ${ }^{13,14,15}$. Satisfaction with their major is negatively affected by students' feelings of social isolation and the perception that social life would be improved in a different major ${ }^{16}$.

In response to such findings, it has been suggested that colleges can help reduce the gender gap in engineering (and other sciences) by working to create a more cooperative, interactive and welcoming environment, especially for women ${ }^{1,16,17,18,19}$. Adelman ${ }^{3}$ suggests that integrating experiences in the real-world social context of engineering would help retain more students in engineering, both male and female. Programs following such guidelines seem to be more successful in retaining females committed to their field of science or engineering ${ }^{20,21,22}$. However, many of the innovations that have been instituted have been targeted at women specifically, and evaluated primarily for their impact on women ${ }^{16}$. While overall curriculum reform has been advocated, few programs have incorporated such reform on a broad basis, and little evaluation has been done to determine what impact such curricular changes have. It is therefore important to determine the impact of programmatic and climate changes on the experience of engineering students in general and gender differences among them in particular.

With these considerations in mind, it is particularly interesting to focus on engineering students at Rowan University, which offers a somewhat unique setting among engineering schools. Since its recent inception in 1996, the Rowan University College of Engineering has made many efforts to establish an infrastructure comfortable and nurturing to undergraduate students, female as well as male. Its basic hallmarks directly address a number of the institutional factors cited as diminishing satisfaction with the major and in particular, women's persistence in the field (www.rowan.edu/engineering). A central feature of the Rowan program is the concept of the Engineering Clinic, loosely modeled after the medical education model, where students work in small interdisciplinary teams on hands-on projects often directly partnered with industry. In these clinics faculty work closely with students throughout each semester of the undergraduate years ${ }^{23}$. This clinic set-up addresses some of the major problems identified for women in more traditional engineering schools: impersonality and alienation from faculty; direct hands-on "real world" laboratory and teamwork experience in every semester of the four-year program, entrepreneurial expertise. Instead of an emphasis on competition between individuals, much of the work is organized in project teams replicating real-world interdisciplinary collaboration; usually these teams are set up to avoid having only one female with multiple males, although interest in the project may supercede the gender composition, especially in the more advanced years. Nearly $2 / 3$ of Rowan's juniors and seniors have the opportunity to do summer internships, gaining further real-world experience. Rowan prides itself on its low student-faculty ratio and its high level of student-faculty interaction. Relatively small class size (maximum of 35) and faculty accessibility promote this spirit. A strong sense of community is fostered in the engineering school, where the students spend most of their educational careers, relatively isolated from the rest of campus, and with long hours spent not only on coursework but laboratory work outside of class, counteracting the alienation and impersonality complained of in more traditional engineering settings. With approximately $20 \%$ of the faculty female (and, at present, a female dean), female role models are more visible than they are nationally (the national average is $4.5 \%$ female faculty).

"Proceedings of the 2002 American Society for Engineering Education Annual Conference \& Exposition Copyright (C) 2002, American Society for Engineering Education” 
Whether these features actually have the desired impact on students, however, cannot simply be assumed. Rowan developed its curriculum and pedagogy as best practices in engineering education, not for women only. The present paper poses the question of how the students react to the program and climate at Rowan. We focus on gender differences in the evaluation of the programmatic elements and climate issues.

\section{The Present Study}

This paper presents results from an NSF-funded study focusing on gender differences among students in Rowan's Engineering College. Survey questionnaires were administered at the beginning and at the end of the academic year 2000-1 to all students in required major courses (approximately 350 - 106 firstyear students, 105 sophomores, 83 juniors and 61 seniors - of whom about $20 \%$ are female), ensuring a relatively high percentage of participation by the students. This reduced the self-selection inherent in voluntary participation in web-based surveys, for instance, or mail surveys whose response rate is much lower. The findings thus represent a good cross-section of the engineering students, not just the most committed or interested in engineering, nor only the ones with major complaints to voice.

At the beginning of the year, baseline survey data was collected, including family background, precollege preparation both formal and extra-curricular, self-assessments of strengths and weaknesses, and learning style preferences. Analysis of gender differences in background variables has shown that male and female students entered Rowan with very similar backgrounds, differing little in terms of their academic math and science preparation, their SAT scores, their high school extra curricular science and math activities, the support of their family, friends, and high school staff for their engineering pursuits, or their role models in their immediate family. On almost all variables, female students had as strong or stronger backgrounds than male students. ${ }^{29}$

Attitudes toward engineering as a field of study and as a career, perceptions of difficulties for women in engineering, and future plans and commitment to engineering were also collected at the beginning of the academic year. At the end of the academic year, students were asked for their perception of the climate at Rowan, their satisfaction and dissatisfaction with specific aspects of the program, their participation in various types of activities over the course of the year, their attitudes toward engineering at this point in time, and future plans and commitment to engineering. For purposes of comparability, the surveys were designed after reviewing several other survey instruments used in recent studies and incorporating elements from them. ${ }^{1}$ Focus group interviews with about a third of the female students and interviews with faculty filled in some of the understanding of female experiences in the program; most of the results from these qualitative interviews will be presented in a subsequent paper.

In this paper we focus on gender differences in satisfaction with various aspects of the Rowan engineering program. Students were asked to respond to over 30 questions evaluating programmatic elements of the Rowan program and climate issues regarding fellow students and faculty-student interaction. We consider how satisfied students are with programmatic elements in the curriculum, whether male and female students alike perceive the close student-faculty interaction that Rowan purports to have, and how satisfied students are with their peer relationships. After describing very

\footnotetext{
${ }^{1}$ Elements from the Pittsburgh Survey (http://civeng1.civ.pitt.edu/ outcomes/samplequestion.html), the CIRP survey (www.gseis.ucla.edu/heri/cirp_survey_instrument.htm), the Pathways survey ${ }^{30}$, the University of Michigan survey (courtesy of Cinda-Sue Davis and Russell Hathaway), the WEPAN climate study ${ }^{13}$ and the WECE survey (see www.grginc.com) were incorporated into the survey instruments, as well as some original questions (the questionnaire is available from the author by request).
}

"Proceedings of the 2002 American Society for Engineering Education Annual Conference \& Exposition Copyright (C) 2002, American Society for Engineering Education” 
briefly the indicators derived from factor analysis of these items (more detail can be found in the Appendix), we present the gender differences in satisfaction in each of these areas for all students, we then consider the extent to which these gender differences persist in all years of the program, and conclude with a discussion of the implications of the results and directions for future research.

\section{Indicators}

Student satisfaction with their undergraduate engineering experience was broken down into seven indicators using the factor analysis method. Three content areas resulted from the factor analysis: satisfaction with the requirements of the program, satisfaction with the applied part of the program, and satisfaction with climate issues. Within the first content area of programmatic demands, the factor analysis indicated two factors: the first (SATCLASS) indicated satisfaction with the demands related to coursework; the second (SATCHOICE) indicated satisfaction with the choices students had within the program. With the second content area of the applied part of the program, the factor analysis indicated three factors: the first (SATLAB) indicated satisfaction with laboratory work; the second (SATTEAM) indicated satisfaction with teamwork required in the courses; the third (SATCLINIC) indicated satisfaction with the engineering clinic program used at Rowan. With the third content area of climate, the factor analysis indicated two factors, the first (SATPEERS) related to satisfaction with peer relationships and the second (SATFAC) related to satisfaction with faculty-student interactions. The range of scores for each factor is about 0-9, going from low satisfaction to high satisfaction. (More details on the factors can be found in the Appendix.)

\section{Gender Differences in Satisfaction}

Generally we find that female students are more satisfied with the program than are the male students. On almost all of the satisfaction factors, female students are more satisfied than male students. On no factor with a statistically significant gender difference are female students less satisfied. The mean scores on all 7 factors are presented in Table 1 by gender.

In the following we look more closely at gender differences in each of the different factors of satisfaction.

\section{Programmatic Elements:}

On the first two programmatic elements, dealing with satisfaction with the coursework load and the amount of choice available in the program, female students are more satisfied than male students.

\section{a. Satisfaction with classwork demands (SATCLASS)}

Female students are satisfied classwork issues than are male students. The mean score for females was 5.19 compared to 4.95 for males, the t-test showing a significance of $\mathrm{p}<.10$. (Table 2) To make this less abstract, we can look at one of the items with high loading on this factor, the pace in required courses. While $29.3 \%$ of the male students disagreed that the pace in required courses is too fast, $44.8 \%$ of the women disagreed.

The significance of this finding is greater when put in the context of previous research. WEPAN's Pilot Climate Survey of more than 8000 male and female undergraduate engineering students from 29 institutions found that women were significantly more likely to be overwhelmed by the fast pace and heavy workload of engineering than were male students ${ }^{13}$. 
TABLE 1

\section{SATISFACTION WITH PROGRAMMATIC AND CLIMATE ASPECTS OF ROWAN'S ENGINEERING PROGRAM: DESCRIPTION OF FACTORS AND MEAN SCORES BY GENDER}

(Means on Factor Scores; T-Test on Difference in Mean Scores between Males and Females)

\begin{tabular}{|c|c|c|c|c|}
\hline \multirow[t]{2}{*}{ SATISFACTION FACTOR } & \multirow[t]{2}{*}{ SATISFACTION WITH: } & \multicolumn{2}{|c|}{ GENDER } & \multirow{2}{*}{$\begin{array}{c}\text { T-TEST } \\
\text { SIGNIFICANCE } \\
\end{array}$} \\
\hline & & $\mathbf{M}$ & $\mathbf{F}$ & \\
\hline $\begin{array}{c}\text { Programmatic Issues: } \\
\text { SATCLASS }\end{array}$ & $\begin{array}{l}\text { Coursework load and pace, } \\
\text { expectations of professors, attention } \\
\text { to learning styles in classroom }\end{array}$ & 4.95 & 5.18 & $.094^{*}$ \\
\hline SATCHOICE & $\begin{array}{l}\text { Choice of classes, internship } \\
\text { opportunities, advising }\end{array}$ & 4.95 & 5.19 & $.019^{* *}$ \\
\hline $\begin{array}{l}\text { Applied Part of Program: } \\
\text { SATLAB }\end{array}$ & Lab work & 5.09 & 4.98 & .422 \\
\hline SATTEAM & Group work in classes & 4.93 & 5.23 & $.033^{* *}$ \\
\hline SATCLINIC & Engineering clinic & 4.95 & 5.19 & $.072^{*}$ \\
\hline $\begin{array}{r}\text { Climate Issues: } \\
\text { SATPEERS }\end{array}$ & Peer relationships & 4.98 & 5.28 & $.010^{* *}$ \\
\hline SATFAC & Faculty-student relationships & 5.01 & 4.97 & .794 \\
\hline (n) & & $(246)$ & $(67)$ & \\
\hline
\end{tabular}

T-test of means significant at $\mathrm{p}<.10$.

${ }^{* * *}$ T-test of means significant at $\mathrm{p}<.05$.

\section{b. Satisfaction with choices available (SATCHOICE)}

The female students are significantly more satisfied than are the males with the amount of choice available in the engineering program. Their mean score on this indicator is 5,19, compared to males' 4.95 (the t-test showed significance at $\mathrm{p}<.05$ ). More specifically, we can look at two of the questions with high loading on this factor: $62.7 \%$ of the female students agreed they could get the classes they needed in the semester they wanted, compared to only $46 \%$ of the male students; $38.8 \%$ of the female students strongly agreed that ample internship opportunities were offered, while only $22.9 \%$ of the male students strongly agreed with this.

It should be noted that while we do not have data on the actual opportunities and choices offered to male and female students, there is no indication that differential opportunities are actually available, since there is no significant gender difference in the proportion actually having summer internships among upper division students (Hartman \& $\operatorname{Hartman}^{28}$ ). However, the females are more satisfied with their 
perception of this aspect of the program than are the male students. It is, of course, possible that fewer females are looking for internships, or particular classes that are hard to get; but we have no evidence that this would be the case.

\section{Applied Part of Program:}

With regard to the applied aspects of the program, females are more satisfied on two of the three indicators; on the third, there is no significant gender difference.

\section{a. Labwork (SATLAB)}

There is no gender gap in satisfaction with laboratory work. The mean score for males is 5.09, and for females, 4.98 (not a statistically significant difference). To make this more concrete, consider two of the questions with high loading on this factor: men and women are as likely to feel that lab work adds a lot to their understanding of course material, and also that more lab experience would be worthwhile.

The lack of gender difference with regards to lab work gains importance when compared to the WEPAN study, which showed that female students were significantly less comfortable in the lab than were male students $^{13}$. A lack of gender difference therefore indicates a better engineering environment for women in this respect, in comparison to the more traditional programs.

\section{b. Teamwork (SATTEAM)}

In their evaluations of teamwork, female students were more satisfied than male students. Their mean score on this factor was 5.23, compared to males' mean score of 4.93 (the t-test was significant at $\mathrm{p}<.05)$. More specifically, responses to one of the questions with high loading on this factor show that less than a third of the female students thought too much group work was required in engineering classes, compared to over half of the male students. Female students are also more likely than male students to say that working in assigned teams helps them understand the material in class, or to think that teamwork slows down the learning process in the engineering clinics.

Previous research has suggested that women in particular respond favorably to cooperative learning and group work in class ${ }^{7,24,25}$; while the differences are small, our findings reinforce this notion.

\section{c. Satisfaction with the engineering clinic (SATCLINIC)}

Female students are more positive in their appraisal of the clinic system than are the male students. Their mean score on this indicator is 5.19, compared to males' 4.95 (the t-test was significant at $\mathrm{p}<.05$ ).

Considering some of the specific indicators included in this assessment of the clinic system: over a third of the female students strongly agree that clinic projects provide useful hands-on experience in engineering, compared to $1 / 5$ of the male students. Over a third of the females strongly agree that the clinic projects give good teamwork experience, compared to $27.2 \%$ of the males.

While the engineering clinic system was not designed specifically with females in mind, its incorporation of hands-on projects accomplished in multi-disciplinary teams, with a holistic approach to learning and entrepreneurial experiences are features we would expect to have benefits that the female students are particularly attuned to, since the literature has called for these kinds of innovations to make engineering more "female-friendly"12,17. Our findings suggest that this is indeed the case, as the females are particularly satisfied with the system.

\section{Climate Issues}

With regard to the engineering climate, females are more satisfied than males are with their peer relationships, but there is no significant difference in satisfaction with faculty-student relationships.

"Proceedings of the 2002 American Society for Engineering Education Annual Conference \& Exposition Copyright (C) 2002, American Society for Engineering Education” 


\section{a. Satisfaction with peer relationships (SATPEERS)}

Female students are more satisfied with their peer relationships than are males: their mean score on the SATPEERS factor is 5.28, compared to males' 4.98 (the t-test is significant at $\mathrm{p}<.05$ ). To make this more concrete, we look at some of the questions with high loading on this factor: while $53 \%$ of the males are proud to be engineering students and 50\% strongly agree that students feel a sense of community in the Engineering College, $73.1 \%$ and $71.6 \%$ of the female students do, respectively. While $40 \%$ of the males strongly agree that students help each other on coursework projects and ideas, $62.7 \%$ of the female students do. While about $30 \%$ of the males feel that fellow students are approachable and friendly, over $40 \%$ of the female students do.

The literature points out that satisfactory peer relationships may be the "single most potent source of influence on growth and development during the undergraduate years" (p. 398) ${ }^{1}$, and the importance of a community of fellow engineering students has been seen as critical in reducing female attrition from science and engineering fields ${ }^{2,14,26}$. Female satisfaction with their peer relationships is therefore sn important finding.

Unfortunately, from these questions we do not know whether most women are referring to peer relationships with women or men or a mixture. However, from the focus group interviews, there does not seem to be a consistent pattern: some women associate mainly with other women, while others associate with mixed genders, and a few associate mainly with male students.

\section{b. Faculty-Student Relationships (SATFAC)}

In terms of satisfaction with faculty-student relationships, there is no gender difference. With a mean score of 4.97, female students are not significantly different in this respect from males, whose mean score is 5.01. Faculty are perceived as being as responsive to female as to male students. The individual questions show us that faculty are equally perceived by females and males as likely to listen to them when they are troubled, show them respect, and give them helpful feedback. The faculty have undertaken to be very dedicated to undergraduate education and very accessible to students (as stated in faculty interviews with the author); it appears that they are perceived as such by male and female students alike.

Frequent student interaction with faculty has been shown to have positive effects on student development, involvement and retention; however, students in a nation-wide sample of institutions found that faculty-student interaction in the field of engineering was less favorable than in other fields of study ${ }^{1}$. Our data suggest that both males and females perceive their interaction with engineering faculty favorably at Rowan, and that there is no gender difference in this respect.

Summing up the gender differences in satisfaction with the Rowan program, female students tend to be as satisfied or more with all of the measured aspects of the program than are male students: this has been shown with regard to climate issues regarding peer and faculty-student relationships, as well as programmatic elements including the in-class and curricular demands of the program and the applied aspects of lab work, team work, and engineering clinic. It should be noted that where the gender differences are statistically significant, they are fairly small, and are of a similar magnitude for each of the factors.

\section{Variation in Gender Differences by Year in the Program}

In this section we look at the variation in gender differences by year in the program. There are a number of reasons to expect gender differences to vary according to year in the program. The WEPAN Climate 
Pilot study found, for instance, that gender differences regarding the fast pace and heavy workload in engineering classes were smallest for seniors ${ }^{13}$. On the other hand, Felder et. al. ${ }^{25}$ found that experiences with teamwork became more negative for women over several semesters, whereas their experiences were more positive in the first semester. We therefore were prompted to examine whether gender differences in satisfaction with these various elements of the Rowan program remain constant in the different years of the program.

It should be cautioned, however, that at this point we are not examining panel data but cross-sectional data. We thus do not have the change in satisfaction of the same student from one year to the next, but only a comparison of students at different levels at a particular point in time. ${ }^{2} \mathrm{We}$ can only infer changes over the undergraduate career from the cross-sectional differences we find between cohorts at this one point in time. Since almost all of the engineering students started out in this program as first-year students, however, year in the program does reflect for the most part the number of years of exposure to the Rowan program. It does not, however, control for changes in the program that may have occurred at various stages of these years, and thus is a very rough proxy for more precise measurement of changes over the course of the undergraduate career.

Generally we do find that the gender gap in satisfaction is different at the various levels of the program; the differences, however, are not all in the same direction, as will be explained below.

\section{Programmatic Elements}

\section{a-b. Satisfaction with classwork demands (SATCLASS) and choices available (SATCHOICE)}

In terms of the programmatic elements of both program demands and choices, the gender gap in satisfaction is greater for upper division students, particular for juniors. (Figures 1 and 2) In fact, the gender

differences on these factors are not statistically significant among lower division students ( $t$-tests of gender differences among lower division students are not significant for either factor). On both of these indicators, satisfaction with the program is higher at the end of the program than in the earlier years of the program, for both males and females. Partly this is due to more dissatisfied students dropping out (although the rate of attrition is relatively low) ${ }^{3}$; partly it is because students who are at higher levels of the program have been in the program longer and are more familiar with it. Among upper division students, females are significantly more favorable in their opinions about these aspects of the program than are males, and the graph shows us that this is especially true during the junior year. Junior males are not as satisfied as first-year males in terms of coursework, and are just as satisfied but not more with regard to the choice factor. In contrast, junior and senior females are much more satisfied with both programmatic aspects than are lower division females. As a result, the gender gap in satisfaction, with females being more satisfied than males, is greatest for the junior year.

\footnotetext{
${ }^{2}$ The survey is continuing this year, and hopefully will continue to at least follow one cohort of students through their four years. Then we will be able to actually speak of "change" in satisfaction.

${ }^{3}$ First year retention has averaged $85 \%$ for the first 5 years of the College. Female first-year retention rate is on the average higher than for the males.
}

"Proceedings of the 2002 American Society for Engineering Education Annual Conference \& Exposition Copyright (C) 2002, American Society for Engineering Education” 


\section{FIGURE 1}

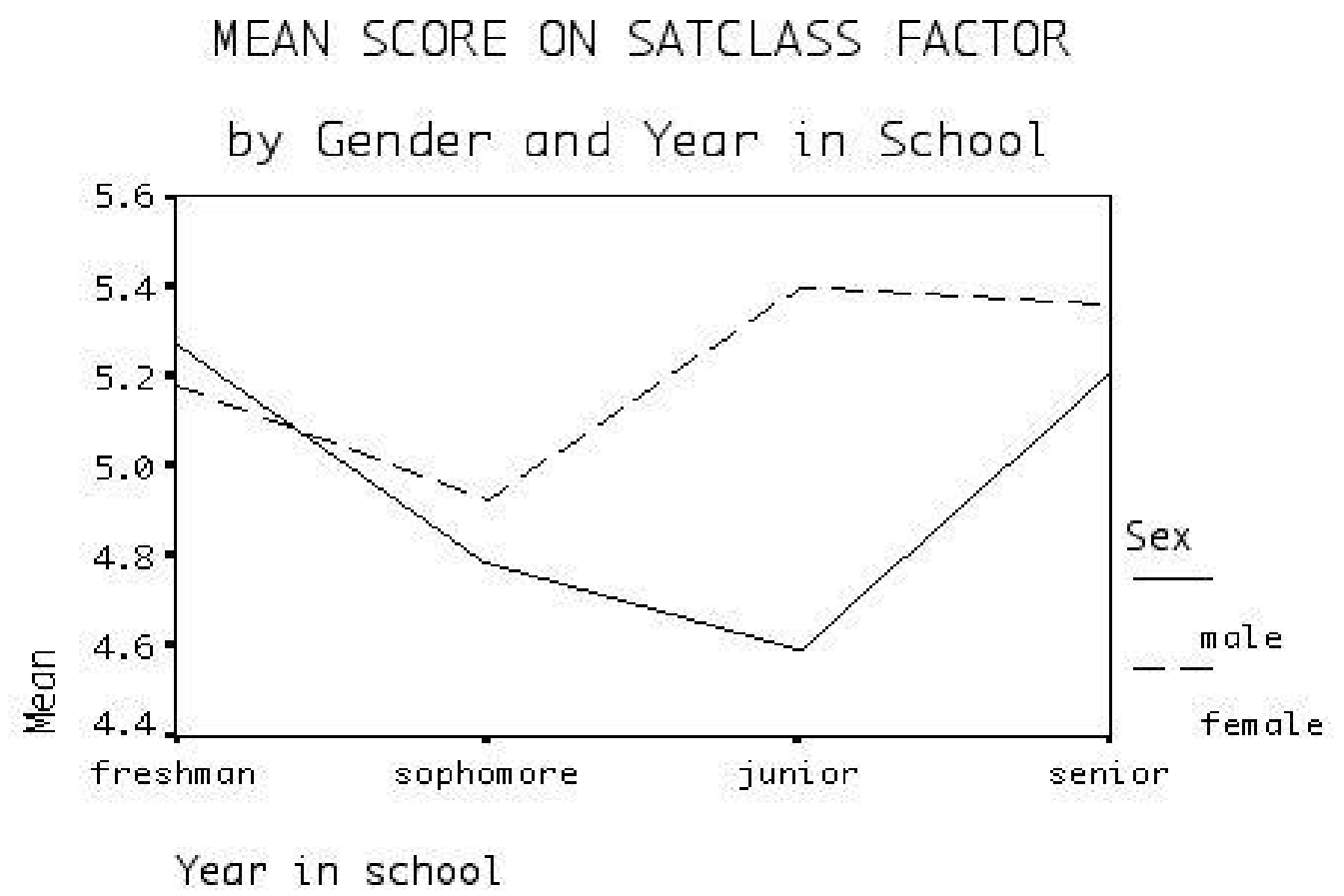

FIGURE 2

MEAN SCORE ON SATCHOICE FACTOR

by Gender and Year in School

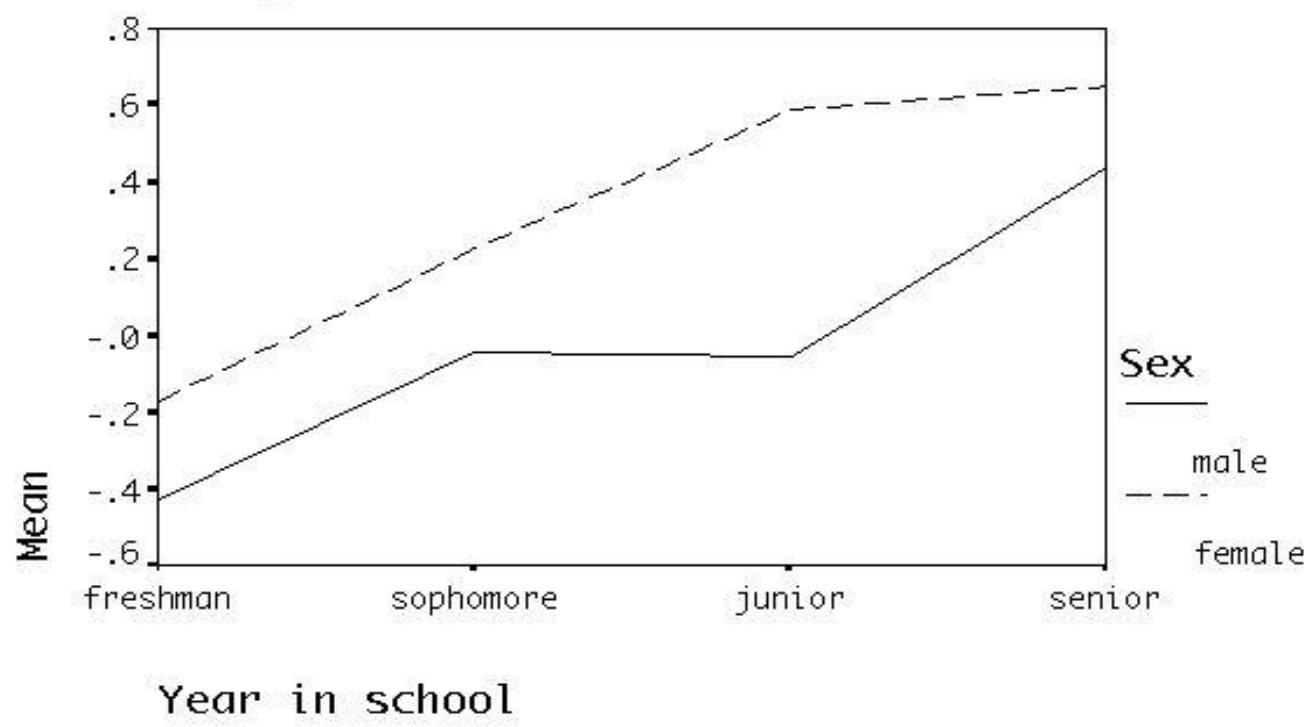

"Proceedings of the 2002 American Society for Engineering Education Annual Conference \& Exposition Copyright (C) 2002, American Society for Engineering Education” 


\section{Satisfaction with Applied Aspects of the Program (SATLAB, SATTEAM, AND SATCLINIC)}

\section{a. SATLAB}

While overall there is no gender gap in satisfaction with lab work, we can see that the overall mean camouflages considerable differences among the students (Figure 3). Female variation in level of satisfaction with lab work is much greater than among male students: there is a curvilinear relationship with year in the program for females, showing that first-year students and senior students are more satisfied with lab work, while sophomore and junior students are the least satisfied. Among males, there is less difference in satisfaction between the different years of the program.

Both male and female sophomores are less satisfied with lab work than are first-year students, and this change is especially great for female students, who are comparatively well satisfied with the lab work encountered in the first year. This lack of satisfaction in the sophomore year is intensified among females in the junior year, where the level of satisfaction in this respect is at its lowest. Junior males, on the other hand, seem to have "recovered" from the sophomore "shock", and have a level of satisfaction similar to the first-year and senior year. Thus, in the sophomore year, gender differences disappear; but in the junior year, females are considerably less satisfied with lab work than are the male students; and in the senior year, there is again little gender difference.

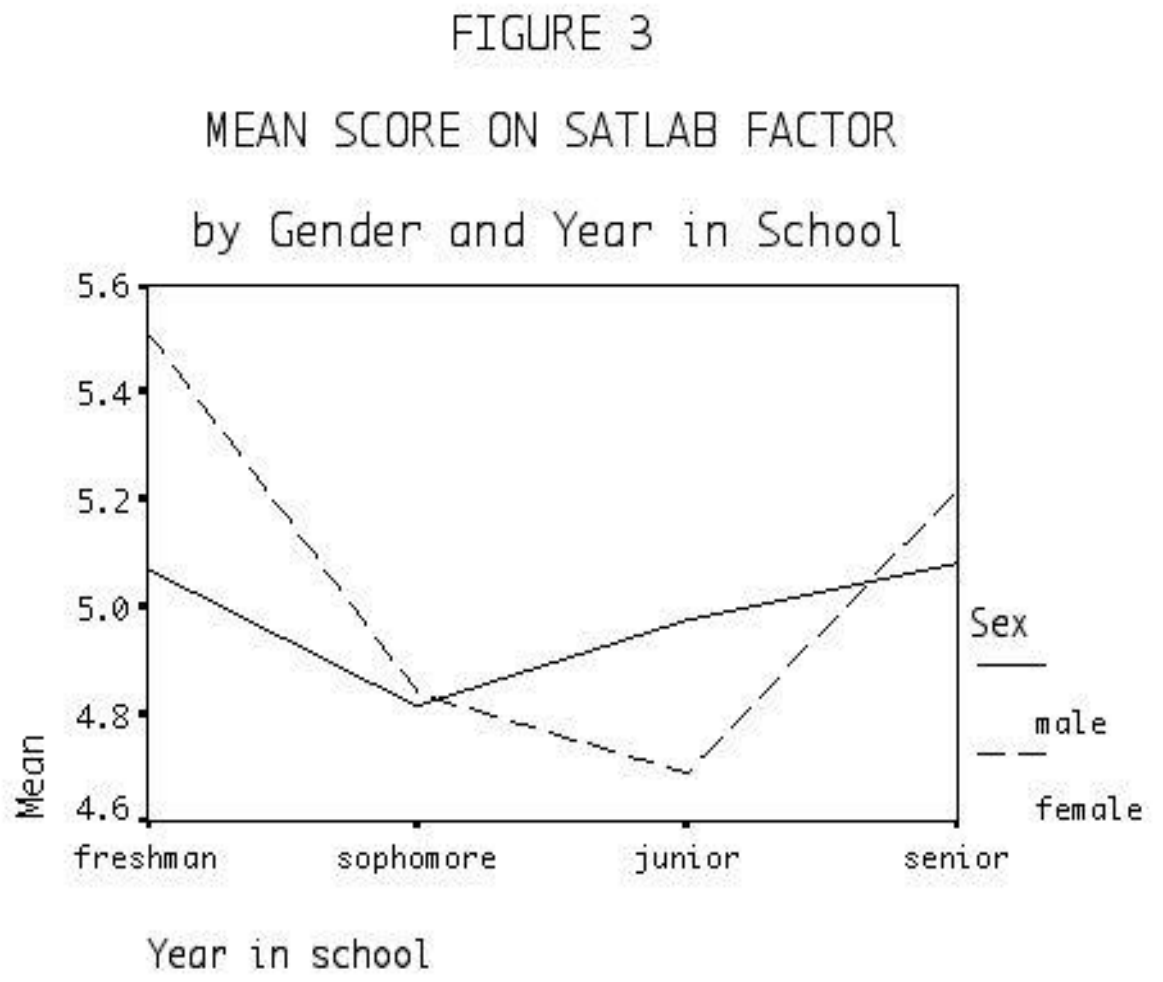

This fluctuation in satisfaction with the lab work could be related to the type of lab work required in these various years; it might be related to the particular mix of majors or other characteristics during any of these cohorts; it might be related to differential attrition in the various years; or it could reflect changes in the way lab work is administered during the different years of the program. Further analysis will be necessary to explain this finding.

"Proceedings of the 2002 American Society for Engineering Education Annual Conference \& Exposition Copyright (C) 2002, American Society for Engineering Education” 


\section{b. SATTEAM}

Females are more satisfied than males with team work up until the senior year (Figure 4). Female satisfaction with teamwork does decrease slightly with each year in the program, but until the senior year is at a significantly higher level than that of males; however, senior males seem to be much more favorable toward teamwork than males at other years, so there is virtually no gender gap during the senior year. The reason for this difference will be interesting to explore, as it may give a clue as to how to improve the teamwork experience for males at other levels of the program.

It should be noted that these findings lend mild support to those of Felder et. al. ${ }^{25}$, who, in their longitudinal study of cooperative learning among engineering students, found that females became less enamored with group work as time went on. In our sample, the level of satisfaction with teamwork is lower for each successive year, but the differences are quite small.

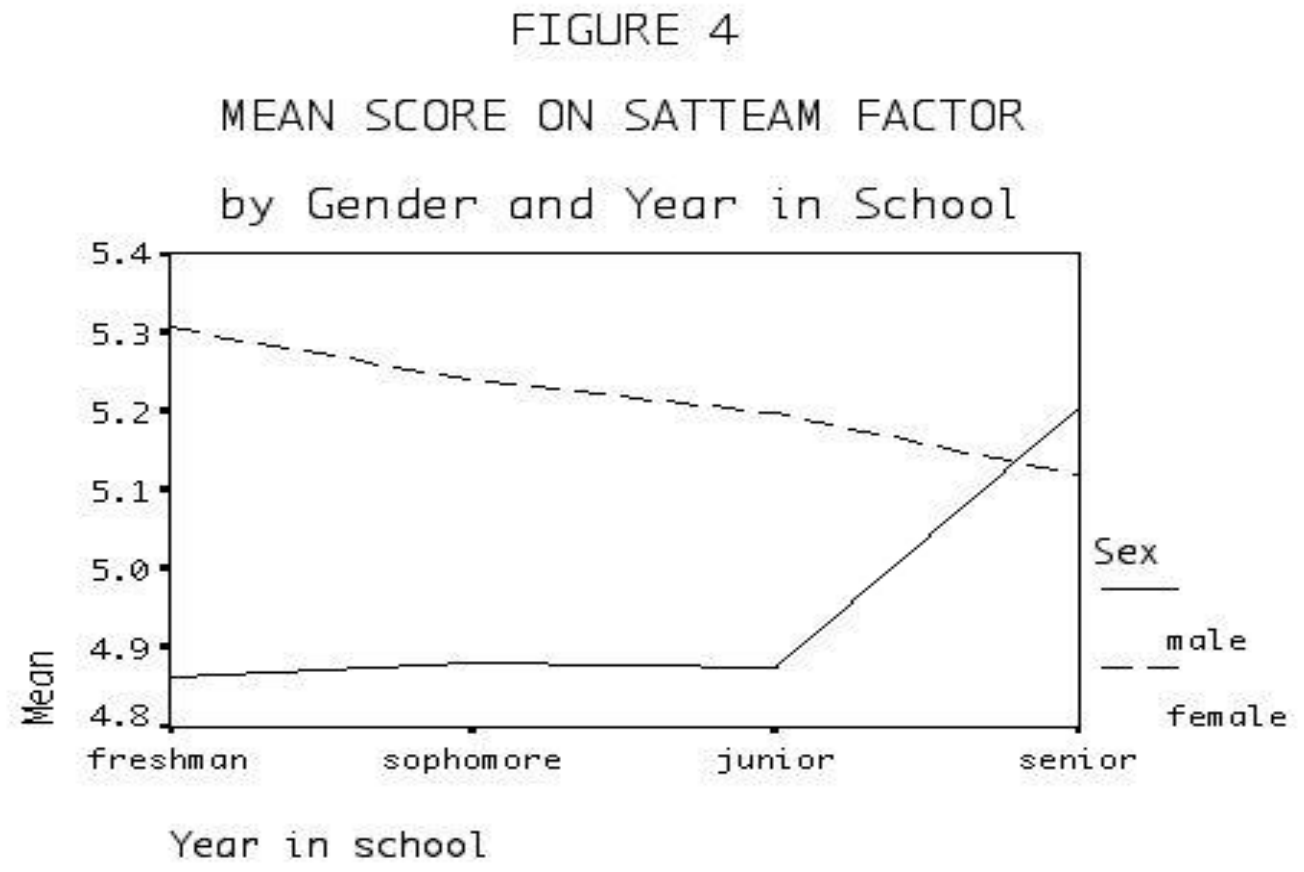

\section{c. SATCLINIC}

Gender differences in satisfaction with the clinic system are mainly among first-year students (Figure 5). The greater satisfaction of females with the clinic system is considerably less among sophomores and practically nonexistent among juniors and seniors. Among females, satisfaction with clinic is lowest for juniors, and considerably higher among seniors. For both males and females, seniors express the most satisfaction with the clinic system.

"Proceedings of the 2002 American Society for Engineering Education Annual Conference \& Exposition Copyright (C) 2002, American Society for Engineering Education” 


\section{FIGURE 5}

\section{MEAN SCORE ON SATCLINIC FACTOR}

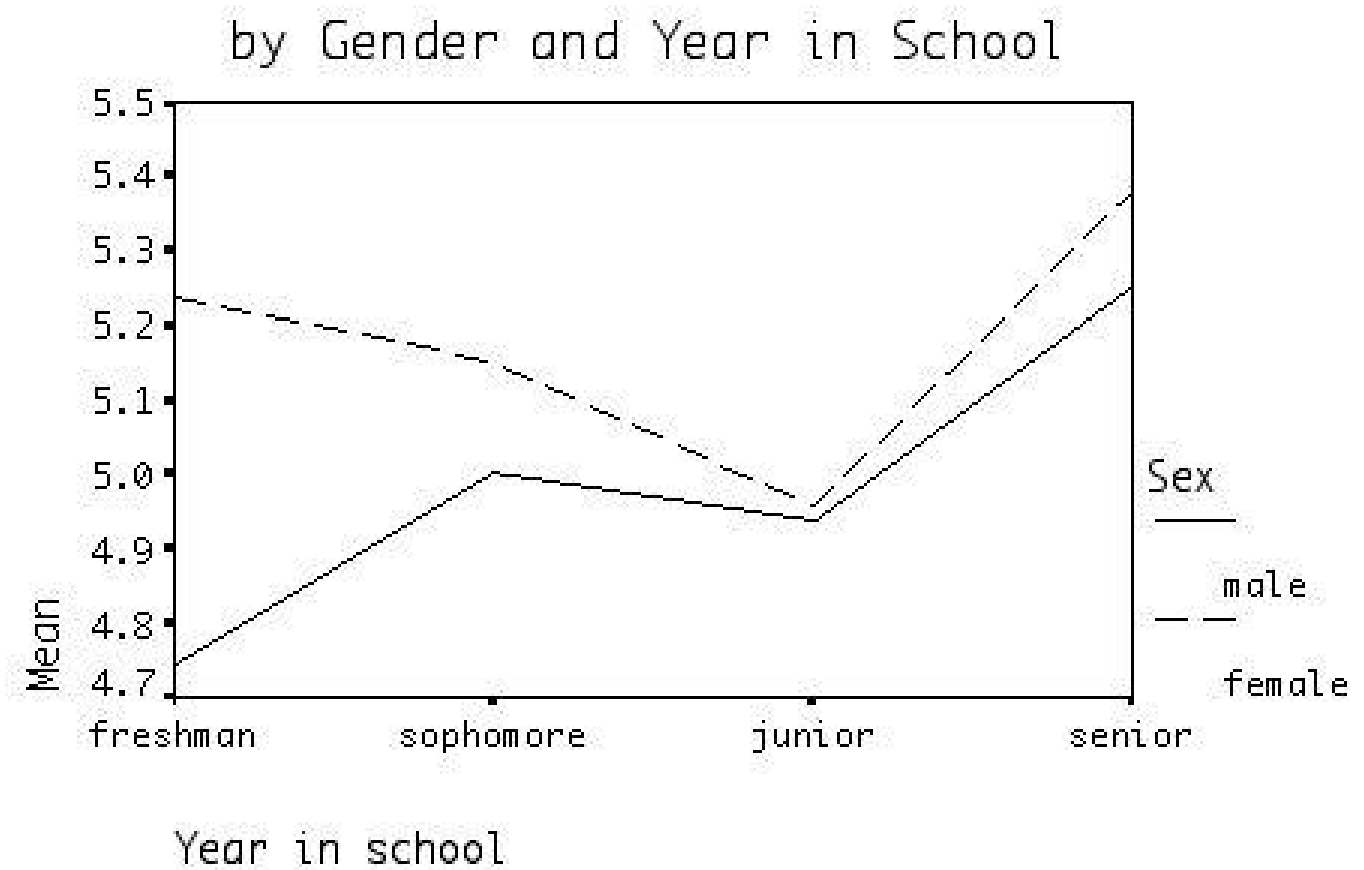

Summarizing our findings about the gender differences in satisfaction with applied aspects of the Rowan program over the different years of the program, we found that gender differences in satisfaction exist even after we control for year, and quite a bit of variation is found in those gender differences over the years. While the patterns of difference vary over the three factors, this much they have in common: for all three indicators, the gender differences are greater among lower division students, and least among senior students. However, the fluctuation of satisfaction is quite considerable for females when it comes to lab work, and for males when it comes to team and clinic work.

\section{Climate Issues}

On the climate issues even more than on the programmatic issues, we have difficulty separating the effect of the particular mix of students in any particular year or cohort, and the changes that develop as a result of being in the program longer. Rather than draw misleading conclusions, we simply note that satisfaction with peer relationships fluctuates considerably for both male and female students, without out a clearly understood pattern. We believe that drawing conclusions about this should wait for panel data, which will show the development of satisfaction with peer relationships for the same group of students as they stay in the program.

\footnotetext{
"Proceedings of the 2002 American Society for Engineering Education Annual Conference \& Exposition Copyright (C) 2002, American Society for Engineering Education”
} 


\section{b. Satisfaction with Faculty-Student Interaction (SATFAC)}

With regard to satisfaction with faculty-student interaction, there is relatively little gender difference over the course of the undergraduate years (Table 2). The one exception appears in the sophomore year, when females perceive less satisfactory faculty-student relations than in other years. Although female students start out with higher satisfaction in their first year with faculty-student interaction, this seems to plummet during the sophomore year. Again, whether this is a one-time occurrence or a pattern that will repeat itself is something that further analysis will address.

TABLE 2

\section{MEAN SATISFACTION WITH FACULTY-STUDENT INTERACTION (SATFAC) BY GENDER AND YEAR IN SCHOOL}

\begin{tabular}{|l|c|c|}
\hline \multicolumn{1}{|c|}{ GENDER } & MALE & FEMALE \\
\hline YEAR IN SCHOOL & & 5.53 \\
\hline Freshman & 5.23 & 4.42 \\
\hline Sophomore & 4.92 & 5.05 \\
\hline Junior & 4.88 & 4.86 \\
\hline Senior & 4.93 & \\
\hline
\end{tabular}

\section{Summary \& Conclusions}

We have considered student evaluations of seven aspects of the Rowan engineering program. Two aspects were indicators of the programmatic demands on the students, in the classroom and in the curriculum. Three aspects were indicators of the applied parts of the program (lab work, team work, and the clinic system). Two aspects were indicators of the peer and faculty climate.

On 5 of the 7 factors, females were more satisfied with the Rowan program than were male students (the programmatic elements of demands on the students in the classroom and in the curriculum, the applied aspects of the program in terms of teamwork and the clinic system, and the climate aspect of peer relationships). On 2 of the 7 indicators, there were no gender differences (satisfaction with lab work and satisfaction with faculty-student interactions). On none of the indicators were females significantly less satisfied with the program or the engineering climate.

This difference in satisfaction may mean several things. It may be that the program is designed in such a way that the female students are indeed satisfied with it, but the male students are not. For instance, it may be that the program is not challenging enough or competitive enough for many of the men, who would prefer a more traditional program. Another possibility is that female students express higher satisfaction than male students because females are easier to satisfy or simply are less critical than males, However, in the WEPAN study ${ }^{13}$, women were not as satisfied as men in engineering, suggesting that female satisfaction with engineering programs is not an expected pattern. Another possibility may be that because women have higher GPA's on the average and got better grades in high school, that their academic performance is higher than the men's, and therefore they are more satisfied with the program;

\footnotetext{
"Proceedings of the 2002 American Society for Engineering Education Annual Conference \& Exposition Copyright (C) 2002, American Society for Engineering Education”
} 
that is, even if the program is difficult, because women are stronger academically, they are more satisfied than the male students. Finally, since the women are concentrated in two of the College's majors, it may be that they are more satisfied because students in these majors are, on the whole, more satisfied than students in other majors.

Whatever the explanation (which we will explore in further analyses of the data), it is important to recognize that satisfaction has been directly related to retention in engineering. Adelman ${ }^{3}$, in his longitudinal analysis of transcripts of students who started out in engineering, found that women who leave engineering area less likely to do so because of poor academic performance than because of dissatisfaction with their experience in higher education (based on a composite index of satisfaction with academic aspects of college, non-academic/institutional environment, preparation for work/careers, and costs). So our finding that females are more satisfied with the various aspects of the Rowan program suggests that the Rowan program may indeed have a positive impact on women's staying in engineering.

Our findings reinforce the perception that teamwork is especially "female-friendly" and fosters satisfaction among the female students in particular. The clinic system, based heavily on teamwork, is also "female-friendly". The camaraderie fostered by the teamwork and close interaction with peers is particularly satisfying to the female students, who are more satisfied with peer relationships than are male students.

When we looked at gender differences across the various years of the program, we found that the gender differences in satisfaction were not constant, but varied across the years. This reinforces our expectation that this kind of analysis will be able to clue us in to what elements of the program impact satisfaction among male and female students, especially once we are able to follow the same group of students throughout the program. Broadly speaking, we found two different kinds of patterns. With regard to satisfaction with the programmatic elements of coursework load and choice in the engineering program, gender differences are greater for students who have been in the program longer, with females expressing especially higher satisfaction than males during the junior year. In contrast, with regard to satisfaction with the applied aspects of the program, gender differences are greatest among first year students and are considerably narrower in the later years of the program.

Two kinds of questions are raised by these findings. Because this is cross-sectional data rather than a panel study we are analyzing, it is difficult to be conclusive about whether the observed differences are cohort differences or differences over the course of the undergraduate career. Nor can we be sure of the effect of attrition, or self-selection, which results in a different make-up of upper division cohorts who have stayed with the program. Perhaps the greater satisfaction with elements of the program among upper division females is because weaker female students dropped out early on ${ }^{4}$; perhaps there is a different kind of self-selection occurring among males. Further analysis following the same cohort of students through their experiences in the College will allow us to more precisely understand the changes in satisfaction which occur from one year to the next. When these changes are more precisely identified, we will be able to focus on aspects of the program that can be modified to help either male or female studies to become more satisfied with the program.

The next research question to be asked concerns the impact of these gender differences (or lack thereof) in satisfaction with the program and climate issues. For example, if females are as satisfied or more satisfied than men with these features of the program, will they be more likely to stick with the major

\footnotetext{
${ }^{4}$ Although Adelman ${ }^{3}$ found that it was female students with higher than average academic records who were more likely to drop out of engineering.

"Proceedings of the 2002 American Society for Engineering Education Annual Conference \& Exposition Copyright (C) 2002, American Society for Engineering Education”
} 
and eventually with their careers than females have in more traditional programs? There are two affirmative indications. One is that the average first-year retention rate for female students ( $84 \%$ for the past 4 years) is actually higher than that of male students (79\%), significant in that the national average is a lower retention rate for female than male students ${ }^{3}$. A second indication is that the academic performance of female engineering students at Rowan equals or excels that of the male students, in terms of (self-reported) GPA overall and in engineering (see Hartman \& Hartman) ${ }^{28}$.

However, previous analysis of this data showed that female students have lower self-confidence in their engineering abilities and less commitment to the major than do the male students ${ }^{27}$. This is not unlike findings in more traditional programs. The question is whether the programmatic and climate elements with which women appear to be satisfied are enough to combat these more traditional gender differences. Future analysis of this data as we follow the students through their undergraduate career will enable us to pinpoint when in the system - if at all - female students' commitment weakens (or strengthens) and whether this is at all related to their satisfaction with the Rowan program.

Given the unusual nature of the women's satisfaction with the program (compared to more traditional programs where women have reportedly been less satisfied than men), we might also raise the question of whether making women more satisfied with the program results in men become less satisfied. More specifically, who are the men who are more satisfied with the program and whether the nature of the programmatic elements is in any way disadvantageous to male commitment to engineering. If we find that they are not, we may indeed conclude that many of the programmatic and climate features of the Rowan setting are "best practices in engineering", and not for women only.

\section{Appendix: Satisfaction Factors}

The factors were created using principle-components varimax rotation factor analysis. On each of the factor analyses, the items included showed high communality (.5 or higher) and together explained at least $50 \%$ of the variance of the items. The resulting scores on each factor are standardized with a mean of 0 and a standard deviation of 1 . However, for purposes of presentation the mean was "moved" to 5 so all scores are positive. The questions with high loadings on each factor are described below. A more detailed explanation of the derivation of these factors will be presented in a subsequent paper.

\section{Programmatic Elements:}

The first two indicators address how demanding students perceive the program to be, the first in terms of perceived demands related to classwork and the second reflecting opinions about curricular demands and internship opportunities.

\section{a. Satisfaction with classwork demands (SATCLASS)}

The indicator SATCLASS reflects the extent to which students perceive coursework too be too demanding or difficult. It is based on the extent to which students agreed (on a scale of 1 to 5) to the following items: "The pace of learning in many of the required courses is too fast", "The workload for engineering students is too heavy and difficult", "Many of my classes are too large", "Engineering professors expect students to have better developed computer skills than they actually have", and "Not enough attention is given to different styles of learning in engineering classes."

\section{b. Satisfaction with choices available (SATCHOIC)}

The second indicator of satisfaction with the content of the program reflects the extent to which students are satisfied with the choices they are offered regarding classes and internship opportunities. It includes the extent to which they agreed (on a scale of 1 to 5) that: "I can usually get the classes I need in the semester that I need them", "Departmental advisors do a good job", and "There are ample opportunities offered for student internships in engineering".

"Proceedings of the 2002 American Society for Engineering Education Annual Conference \& Exposition Copyright (C) 2002, American Society for Engineering Education” 
The next three indicators reflect students' satisfaction with the applied aspects of Rowan's program: laboratory work, the emphasis on assigned teamwork, and the engineering clinic system in particular.

\section{Applied Aspects of the Program}

a. Satisfaction with labwork (SATLAB)

The indicator SATLAB reflects the extent to which students were satisfied with their laboratory experiences. The items with high loading on this factor included how strongly the student agreed (on a scale of 1 to 5) that "Lab work adds a lot to my understanding of course material," "Expectations for lab work are explained well," and "More lab experience would be worthwhile."

\section{b. Satisfaction with teamwork (SATTEAM)}

The second indicator of how the Rowan program is applied reflects satisfaction with the teamwork required. It includes the extent to which students agree (on a scale of 1 to 5) with many of the familiar complaints against group work: that they do not enjoy working in assigned groups in class, that "usually not everyone does their fair share," that teamwork "slows down the learning process" in the clinic setting, that their experience in the engineering clinics has made them more negative about working in groups/teams, and that "too much group work is required in engineering classes."

\section{c. Satisfaction with engineering clinic (SATCLINIC)}

The next programmatic factor is the extent to which students are satisfied with the engineering clinic system. It includes the extent to which students agreed (on a scale of 1 to 5) that the clinic system: provides "realistic experiences like in the work world," provides "useful hands-on experience in engineering," enables students "to connect things from different disciplines," "unifies engineering students in the same class but from different majors," has students "spend time on learning material or approaches irrelevant to their major," and that "too much work is expected for the amount of credit given in the clinics" (a frequent complaint that was voiced in the focus groups).

\section{Engineering Climate:}

Two indicators resulted from factor analyses of the climate issues in the Engineering College.

\section{a. Satisfaction with peer relationships (SATPEERS)}

The first indicator reflects satisfaction with peer relationships in the Engineering College. The items with high loading on this factor included: agreement (on a scale of 1 to 5) that engineering students at Rowan usually "care about me as an individual," "listen to me when I am troubled," "show that they respect me," "support and encourage each other," "are friendly," "help each other out on coursework, projects \& ideas," "are approachable," and "feel a sense of community in the Engineering College."

\section{b. Satisfaction with faculty-student interaction (SATFAC)}

The last indicator reflects satisfaction with faculty-student interaction. It included how strongly the student felt that the faculty are approachable, available outside of class, friendly, listen when the student is troubled, support and encourage the student, respect the student, care about the student as an individual, and care whether the student learns the course material. 


\section{References}

1. Astin, A. W. and Astin, H.S. 1993. Undergraduate Science Education: The Impact of Different College Environments on the Educational Pipeline in the Sciences. Los Angeles: HERI UCLA.

2. Strenta, C. A., R. Elliot, R. Adair, M. Marler, and J. Scott . 1994. "Choosing and leaving science in Hihgly Selective Institutions." Research in Higher Education 35(5): 513-47.

3. Adelman, C.1998. Women and Men of the Engineering Path: A Model for Analyses of Undergraduate Careers. Washington, D.C.: U.S. Department of Education.

4. Manis, Jean M., Barbara F. Sloat, Nancy G. Thomas, \& Cinda-Sue Davis. 1989. An Analysis of Factors Affecting Choices of Majors in Science, Mathematics and Engineering at the University of Michigan. University of Michigan, MI: Center for Continuing Education of Women.

5. Pike, Gary R. 1993. "The Relationship between Perceived Learning and Satisfaction with College: An Alternative View." Research in Higher Education 34(1): 23-41.

6. Ross, Karen C. 1994. Women in Engineering: The Undergraduate Years. Ph.D. Dissertation, SUNYAlbany School of Education.

7. Seymour, Elaine and Nancy M. Hewitt. 1997. Talking About Leaving: Why Undergraduates Leave the Sciences. Colorado: Westview Press.

8. Cunningham, Christine M., Cathy Lachapelle, Meredith Thompson, Mario Delci and Irene Goodman. 2000. Paper presented at the Annual meeting of the American Educational research Association, New Orleans.

9. Bergvall, Victoria L., Sheryl A. Sorby, and James B. Worthen. 1994. "Thawing the Freezing Climate for Women in Engineering Education: Views from Both Sides of the Desk" Journal of Women and Minorities in Science and Engineering, vol. 1, pp.323-346.

10. Collins, Deborah, Alan E. Bayer and Deidre A. Hirschfeld, 1996. "Engineering Education for Women: A Chilly Climate?" 1996 WEPAN National Conference Proceedings, pp. 323-8.

11. Ginorio, A.B. 1995. Warming the Climate for Women in Academic Science. Washington, D.C.: Association of American Colleges and Universities.

12. Rosser, Sue V. 1995. "Introduction. Reaching the Majority: Retaining Women in the Pipeline." Pp.1-24 in S. Rosser (ed.), Teaching the Majority: Breaking the Gender Barrier in Science, Mathematics, and Engineering. New York. Teacher's College Press.

13. Brainard, S. G., S. S. Metz, and G. M. Gillmore, 1998. "WEPAN Pilot Climate Survey." http://www.wepan.org/climate.html

14. Hathaway, Russell S., Cinda-Sue Davis, Sally Sharp. 2000. “WISE-RP Rules: Increasing Women's Retention in the Sciences." Paper presented at the Annual Forum of the Association for Institutional Research, Cincinnati, May.

15. Sonnert, Gerhard. 1995. Who Succeeds in Science? New Brunswick, New Jersey: Rutgers University Press.

16. Davis, Cinda-Sue and Sue V. Rosser .1996. "Program and Curricular Interventions." Ch. 7 in CindaSue Davis, Angela b. Ginorio, Carol S. Hollinshead, Barbara B. Lazarus, Paula M. Rayman \& associates, The Equity Equation. San Francisco: Jossey-Bass Publishers.

\footnotetext{
"Proceedings of the 2002 American Society for Engineering Education Annual Conference \& Exposition Copyright (C) 2002, American Society for Engineering Education”
} 
16. Lantz, Alma. 1982. "Women Engineers: Critical Mass, Social Support, and Satisfaction." Engineering Education 72 (5): 295-6.

17. Rosser, Sue V. 1991. Female Friendly Science. Columbia, NY: Teacher's College Press.

18. Tobias, Sheila. 1990. They're Not Dumb, They're Different. Tucson, AZ: Research Corporation.

19. Ware, N.C., Steckler, N.A., and Leserman, J. 1985. "Undergraduate Women: Who Chooses a Science Major?" Journal of Higher Education 56(1): 73-84.

20. Lazarus, Barbara, and Indira Nair. 1996. "Bridging the Gender Gap in Engineering and Science: The case for Institutional Transformation.” WEPAN National Conference Proceedings.

21. Mead, Patricia, Elizabeth Rosenfeld and David Bigio, 1996. "Humanization of the Engineering Curriculum." WEPAN National Conference Proceedings.

22. Nair, Indira and Sara Majetich. 1995. "Physics and Engineering in the Classroom." Pp.25-42 in S. Rosser (ed.), Teaching the Majority: Breaking the Gender Barrier in Science, Mathematics, and Engineering. New York. Teachers College Press.

23. Schmalzel, J., A.J. Marchese, J. Mariappan, and S. Mandayam . 1998. "The Engineering Clinic: A Four-Year Design Sequence. $2^{\text {nd }}$ Annual Conference of National Collegiate Invention and Innovation Alliance. Washington, D.C.

24. Treisman, U. 1992. "Studying Students Studying Calculus: A Look at the Lives of Minority Mathematics Students in College.” The College Mathematics Journal 23(5): 362-72.

25. Felder, R.M., G.N. Felder, M. Mauney, C.E. Hamrin, Jr., and E.J. Dietz, 1995. "A Longitudinal Study of Engineering student Performance and Retention. III. Gender Differences in Student Performance and Attitudes."Jounral of Engineering Education 84:2: 151-174.

26. Seymour, Elaine. 1995. "Revisiting the problem iceberg: Science, mathematics, and engineering students till chilled out: Examining the causes of student attrition in science-based fields on a variety of campuses.Journal of College Science Teaching 24 (6): 392-400.

27. Hartman, Harriet \& Moshe Hartman. 2001. "The Role of Self-Confidence in Undergraduate Engineering Education: Gender Differences at Rowan." Paper presented at the American Sociological Association meetings, Anaheim, August.

28. Hartman, Harriet \& Moshe Hartman, 2002. "Comparing Female and Male Experiences in the Rowan Undergraduate Engineering Program". Paper to be presented at the International Conference of Women in Engineering Society, Ottawa, July.

29. Hartman, Harriet. 2001. "A Gender Lens on Rowan University's College of Engineering." Paper presented at NAMEPA/WEPAN Annual Conference, Alexandria, VA, April.

30. Rayman, Paula, and Belle Brett. 1993. Pathways for Women in the Sciences. Wellesley, MA: Wellesley College Center for Research on Women.

\section{Acknowledgments}

The authors gratefully acknowledge the support of NSF Grant HRD-74857 for this research.

\section{Biographical Information}

"Proceedings of the 2002 American Society for Engineering Education Annual Conference \& Exposition Copyright (C) 2002, American Society for Engineering Education” 
Harriet Hartman is an Associate Professor of Sociology at Rowan University and holds aB.A. in Public Service from UCLA, M.A. in Sociology from University of Michigan, and Ph.D. in Sociology from Hebrew University of Jerusalem. Co-author of Gender Equality and American Jews and articles in gender roles, Jewish studies. She is an Associate Editor of Sociology of Religion.

Moshe Hartman has a visiting position in Sociology at Rowan University. He teaches methods and statistics, stratification, and demography. His B.A. in Statistics is from Hebrew University, M.A. and Ph.D. in Sociology from University of Michigan. He co-authored Gender Equality and American Jews and published numerous articles in stratification, immigration and Jewish studies. 